\title{
The role of contextual factors on participation in the life area of work and employment after rehabilitation: A qualitative study on the views of persons with chronic pain
}

\author{
Thomas Friedli ${ }^{\mathrm{a}, *}$ and Brigitte E. Gantschnig ${ }^{\mathrm{a}, \mathrm{b}}$ \\ ${ }^{a}$ Department of Rheumatology and Immunology, Inselspital, Bern University Hospital, and University of Bern, \\ Bern, Switzerland \\ ${ }^{\mathrm{b}}$ Institute of Occupational Therapy, School of Health Professions, ZHAW Zurich University of Applied Sciences, \\ Zurich, Switzerland
}

Received 16 November 2020

Accepted 7 April 2021

\begin{abstract}
.
BACKGROUND: A deeper understanding of how contextual factors affect the ability to participate in the life area of work and employment despite chronic musculoskeletal pain is needed as a basis for interprofessional rehabilitation programs.

OBJECTIVE: To investigate which contextual factors influence rehabilitation program clients' ability to participate in the life area of work and employment, and how they do this.

METHODS: Nested case study using a realist evaluation framework of interprofessional interventions. Qualitative content analysis of problem-centered interviews to identify influential context-mechanism-outcome configurations.

RESULTS: We identified several important context-mechanism-outcome configurations. In the pre-interventional phase, socioeconomic and environmental factors affected two mechanisms, "exhaustion" and "discrimination". In the intrainterventional phase, the social skills of health professionals and opportunities for discussion with peers affected the ability of program participants to engage with program content. In the post-intervention phase, volitional competences of the social system affected the sustainable application of program content in everyday life.

CONCLUSION: The identified context-mechanism-outcome configurations shows that the ability to participate in the life area of work is interdependent with the ability to participate in other areas of life. In practice and research, assessment and treatment should be carried out based on this understanding.
\end{abstract}

Keywords: Evaluation study, international classification of functioning, disability and health, quality of life, realist evaluation, rehabilitation

\section{Introduction}

*Address for correspondence: Thomas Friedli, Department of Rheumatology and Immunology, Inselspital, Bern University Hospital, and University of Bern, Freiburgstrasse, 3012 Bern, Switzerland. E-mail: tom.friedli@insel.ch.
This study examines the impact of the Bern Ambulatory Interprofessional Rehabilitation program (BAI) on participation in the life area of work and employment for people with chronic musculoskeletal 
pain, at the University Hospital of Bern, Switzerland. In the ICF framework of functioning, disability and health, the term 'life area of work and employment' refers to the ability to stay at work and explicitly includes non-salaried work such as household work, parenting, or volunteer work [1]. Chronic pain is one of the most widespread noncommunicable diseases in western countries [2]. It causes much suffering to people directly affected by it as well as to their relatives. Chronic pain also comes with extremely high health and economic costs. In Europe, economic costs resulting from chronic pain amount to between 3 and 10 percent of the gross domestic product [2]. In the USA, annual costs associated with chronic pain amount to about $\$ 600$ billion, of which about $\$ 300$ billion stem from productivity losses [3]. As a highly complex biopsychosocial phenomenon, chronic pain is most effectively treated through interprofessional programs [4]. Complex interprofessional pain rehabilitation programs often focus on the management of pain and on improving quality of life and workability rather than on achieving total freedom from pain [5]. Outcomes of these programs are thus always dependent on both the intervention itself and on factors external to the intervention (contextual factors).

Two frameworks are relevant to our understanding of contextual factors : 1 . the Framework of the World Health Organization's (WHO) International Classification of Functioning, Disability and Health (ICF) [1] and 2. the realist evaluation approach [6-8].

In the ICF framework, contextual factors are defined as personal and environmental factors that are interdependent with body functions and structures, activities and participation and thus influence the health condition (see Fig. 1). Environmental factors are, for example, relationships and support from others or the attitudes of the social environment.
Person-related factors have not been classified in more detail in the ICF to date. According to Grotkamp et al., these include factors such as the attitudes, basic competences and behavioral habits of a person, or living situation as well as socioeconomic/cultural factors [9].

Realist evaluation is an approach that focuses on the question of whether an intervention leads to change in the everyday lives of those affected. It assumes that each observed effect of an intervention is the result of the interplay with contextual factors, not just the result of the intervention alone [6]. The contextual factors influence one or more mechanisms which lead to various outcomes. The fundamental question of each realist evaluation is: "What works for whom, under what circumstances, in which respect and how?" [7].

In the understanding of a realist evaluation, contextual factors are factors in the environment of a program that influence one or more mechanisms on which the occurrence and expression of various outcomes depend. The interplay of contextual factors, mechanisms and outcomes is summarized in context-mechanism-outcome-configurations (CM OCs). CMOCs are hypotheses about which mechanisms lead to which outcome in which specific contexts - either formulated in advance, or - as in our case-grounded in the data [6].

In short, contextual factors are understood in realist evaluation as individual capabilities of the key actors, interpersonal relationships supporting the intervention, institutional settings or an infrastructural system on a micro-, meso-, or macro-level $[10,11]$.

Mechanisms are hidden but real causal forces leading to outcomes in certain contexts. Westhorp [11] lists five types of mechanisms: powers and

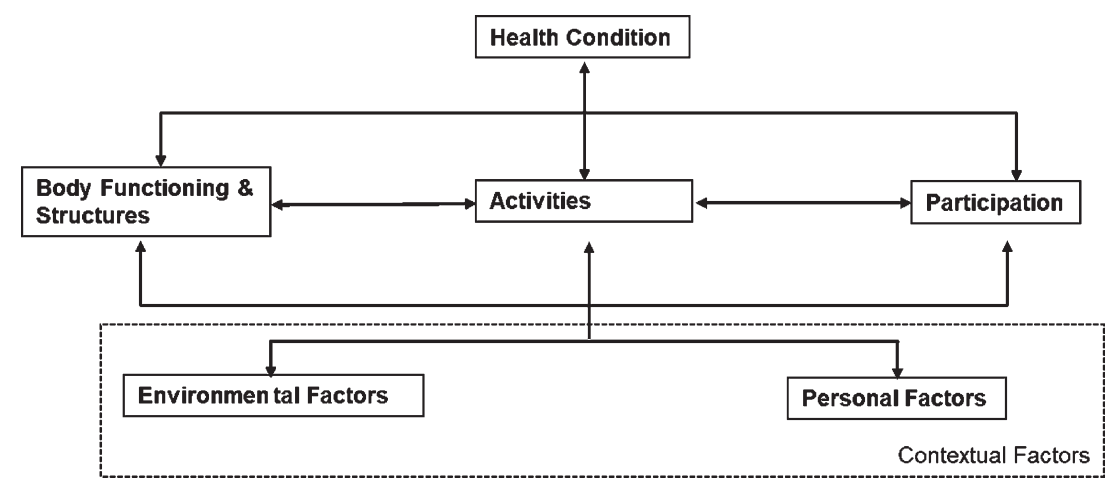

Fig. 1. The ICF Framework of Functioning, Disability and Health. 
liabilities (e.g. motivation), forces (e.g. love or peer pressure), interactions (e.g. contracts), feedback and feedforward processes (e.g. negotiations), reasoning or resources (e.g. logic-in-use).

Against this background, we define contextual factors as personal and environmental factors such as capabilities, relationships, or settings in the program environment that have the power to influence program outcomes.

In line with the ICF, we understand workability as an ability to perform complex activities and to participate in the life area of work and employment [1]. In this understanding, workability includes unpaid activities such as household tasks, childrearing or caring for relatives [12]. Therefore, we do not use the terms workability or 'return to work' in the findings and conclusion, but 'participation in the life area of work and employment'.

In recent years, several quantitative studies have been carried out on the influence of contextual factors on workability (returning to work or staying at work) of people with chronic pain. A comprehensive review of chronic back pain by Allgeier and Bengel in 2018 showed that studies that investigated contextual factors still provide a contradictory picture and that these factors are still insufficiently examined [13]. Indeed, some studies show that contextual factors such as social support or workplace adjustments have an influence on workability $[14,15]$. However, it remains to be seen why and how they play a role in this, and which contextual factors are relevant. Recent qualitative studies related to the influence of contextual factors on returning to work or staying at work often investigated in depth specific contextual factors such as the importance of significant others [16-18]. Others focused on staying at work [19] or barriers within the rehabilitation process. Thus, Patel et al. could for example demonstrate that financial insecurity or barriers within the health care system have an influence on a sustainable return to work [20].

To our knowledge, there has not been a rehabilitation-related investigation of the how and why, the mechanisms of action of contextual factors when people participate in a chronic pain rehabilitation program and what impact this has for the program design. In practice, however, there are numerous rehabilitation programs, which help support people with chronic musculoskeletal pain to be able to return to or remain in the life area of work and employment. Such knowledge would be valuable to ensure that rehabilitation goals can be achieved and rehabilitation services can be developed. One such rehabilitation program is the Bern Ambulatory Interprofessional Rehabilitation program (BAI program) for people with chronic musculoskeletal pain, in which the following research took place. In a cohort study, Gantschnig et al. 2017 showed that participation in the life area of work and employment steadily increased after the completion of the BAI program up to 2 years' follow-up [5]. We now want to know more about for which people, under what circumstances and for what reasons the program does or does not work regarding participation in the life area of work and employment.

Based on this understanding we have developed the following research question:

From the perspective of people with chronic, musculoskeletal pain who participate in an interprofessional rehabilitations program, which contextual factors affect a change in their ability to participate in the life area of work and employment and how does this happen?

\section{Materials and methods}

This study is a nested case study [21] within the evaluation of a complex, interprofessional intervention. As part of a purposeful sampling strategy we have used an extreme-case sampling [21]. We analyzed eight problem-centered interviews in accordance with Kuckartz' method of qualitative content analysis [22].

\subsection{Intervention}

The BAI is a complex rehabilitation program [5]. It is comprised of an intensive phase, a consolidation phase, and a stabilization phase of four weeks each and has been developed on the basis of evidence and international guidelines. The purpose of the phasing is that at every stage of the program, clients can gain more independence in the implementation of what they have learned and are able to apply it in everyday life. The program includes individual and group interventions as well as independent, self-directed exercises on topics such as structuring one's day, changing thought patterns, muscle building or planning for one's professional future. The objective of the program is not to be pain-free, but to better manage the pain, have a higher quality of life and a more satisfactory life conduct. The following professions are part of the treatment team: occupational therapy, medicine (rheumatology), 
Table 1

Demographic characteristics of the participants

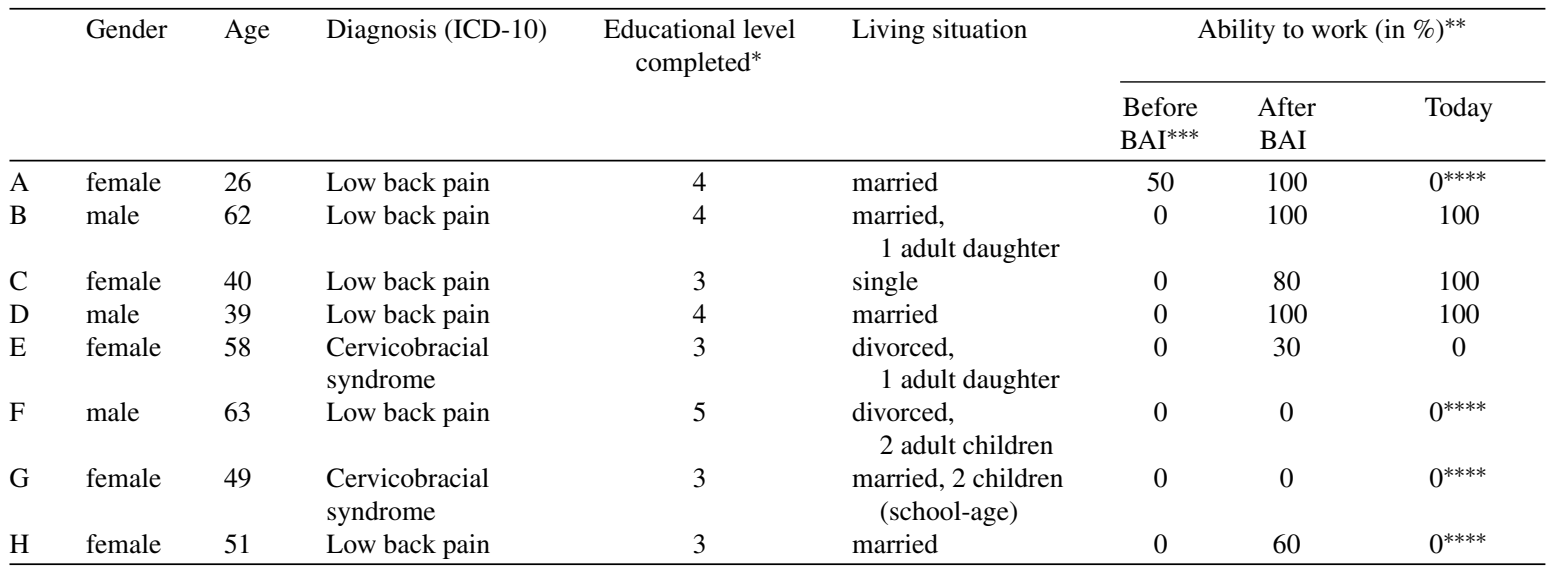

* Educational levels are based on International Standard Classification of Education (ISCED 11) levels of education; at the time of the interviews: $3=$ Upper secondary education, $4=$ post-secondary non-tertiary education, $5=$ Short-cycle tertiary education. ${ }^{* *}$ Indicated as ability to be able to pursue a gainful activity. ${ }^{* * *} \mathrm{BAI}=$ Bern Ambulatory Interprofessional Rehabilitation Program. ${ }^{* * * *}$ reasons other than chronic pain.

physiotherapy, nursing and clinical social work. The program is described in detail elsewhere [5].

\subsection{Sampling and sample}

Extreme case sampling is suitable for our evaluation research approach, as "extreme cases may be information-rich cases precisely because by being unusual they can illuminate both the unusual and the typical" [21]. The clients interviewed in this study had either particularly good or particularly poor results concerning changes in their ability to participate in the life area of work and employment through the BAI program. The sample consisted of eight adults, five women and three men aged 26 to 63 (see Table 1). Participants recruited for the study met the following inclusion criteria: a) participation in one of the first six BAI cohorts; b) of employable age (18-65); c) exceptionally high or low levels of change in the ability to work before and after the program and d) written consent to participation in the study.

\subsection{Data collection}

The study is based on problem-centered interviews [23] with eight of the first 30 participants from the BAI program. The interviews took place from January to May 2019. All interviews were recorded digitally. Immediately after each interview, a postscript was created, in which the interview situation, any particular features of the case and offthe-record statements were recorded. The interviews were transcribed in full and verbatim by the first author from Swiss German dialect into High German.

\subsection{Ethics}

The study was submitted to the Ethics Committee of the Canton of Bern (KEK Bern) and approved in December 2018 (Project ID 2018-01583). Prior to the data collection, all interviewees were informed about the study in detail in writing and verbally. All agreed to participate in writing. During the transcription, all information that could have led to the identification of the interviewees was anonymized. Thereby pseudonyms were assigned to all interviewees and persons named in the interviews. In addition, all other information, such as information about locations or companies was anonymized in such a way that no conclusions could be drawn about the interviewees.

\subsection{Data analysis}

The transcripts were evaluated using Kuckartz's qualitative content analysis method [22]. Content analysis is a systematic, rule-driven, multi-stage method of analysis based on open and axial coding from the well-known grounded theory methodology [24].

The method consists of seven phases. In phase 1 we carefully read the transcripts several times. The reading was accompanied by constantly noting associations and comments in memos. We highlighted 
particularly important text passages and made notes on them in the margin. We then conceptualized these notes at the end of each page (1st abstraction). Next, we used our end-of-page conceptualizations to write a summary of each case based on key words. In phases 2 and 3, we formulated initial drafts of key contextual factors and mechanisms, using the case summaries and the original materials. In doing so, we based our method on open coding, as it is known from grounded theory methodology [24]. Whenever possible, we coded sensory units (at least one sentence). In some cases, we coded related words for keyword-like statements. Phase 2 and 3 coincided in our analysis, as we developed all categories directly from the material. In phase 4, we compiled the coded passages directly in Atlas.ti, with noteworthy elements and important examples still being noted in memos. After coding the first three interviews, we interrupted the coding process for the first time to organize and systematize the codes in Atlas.ti. We repeatedly checked the category system for conclusiveness, plausibility, completeness, and whether it helps to adequately answer the research questions. In the second coding process (phase 6), we defined the final category system, which formed the basis for the work in phase 7, in which we analyzed relationships between the subcategories (in this case as CMOCs). In phase 7, we designed the visual representations of the CMOCs (see Figs. 1-3). From these codes a category system was finally developed with nine categories of contexts and six categories each of mechanisms and outcomes.

The first three transcripts were independently analyzed by the first and the last author and discussed within the team, in order to review intercoder reliability. We found no relevant differences in coding between first author 1 and last author.
In the following section, we present the findings as CMOCs. It has proven useful to structure these chronologically as a pre-, intra- and post-interventional phase. The terms used in the presentation of the findings is based on the ICF [1]; for personal factors not classified in the ICF, it is based on Grotkamp et al. [9]. An exception is the term "life conduct". In our opinion, this term, borrowed from Sommerfeld et al. [25], captures the necessity of actively shaping one's own life and daily routines better than the term 'lifestyle' as used in the ICF. The environmental factors identified in the data material refer to the social environment. Therefore, we have decided to refer to them as social factors in the figures.

\section{Results}

The aim of this study is to better understand the complex interactions between contextual factors and the ability to participate in the life area of work and employment after rehabilitation despite pain as well as to support the further development of pain rehabilitation programs.

\subsection{The pre-interventional phase: Exhaustion and lack of social affirmation}

The data analysis showed that in the preinterventional phase pain-associated exhaustion is a central mechanism in reference to occupational participation (see Fig. 2). In the interviews, the term exhaustion summarized phenomena of great physical or mental fatigue that are connected to the pain, but also the pain-contingent increase in the complexity of everyday life. These are modulated by personal or environmental factors. Ms. G describes this

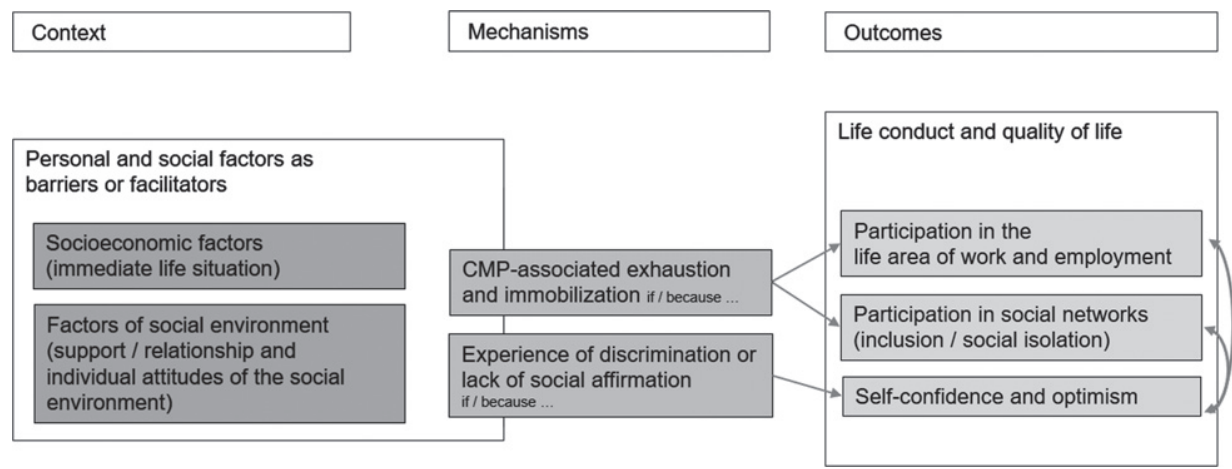

Fig. 2. Pre-interventional CMO configurations. 
pain-contingent increase in the complexity of everyday life as follows: "There are so many things that are actually related that you don't think about if you don't have this [chronic pain, note tf]". She thus describes how everyday activities that are normally automatic, such as household management, are made more difficult and the search for alternative strategies for action needs additional mental, social, physical or psychological resources.

Depending on which facilitating or limiting factors influence life with pain, interviewees report that the energy available for their life conduct is no longer sufficient to sustain all areas of life and that that they only have enough energy left for one or a few areas of life. Whether and how this mechanism is activated is influenced by socioeconomic factors such as one's financial situation, educational level, residence status or employment situation (see Fig. 2). In particular clients who, for example, cannot change jobs due to low education levels or uncertain residence status, and who are existentially dependent on their employment, report attempting to maintain their ability to work for as long as possible without having to seek outside help. This is how Ms. E reports: "(I) have seen to it that I can work as much as I can. (... ) And then it got worse and worse because of the pain, and I worked in spite of it and just said 'I can manage anyway, take tablets and then it's possible'. And at some point it just didn't work anymore". Concentrating one's energy on being able to participate despite pain in the life area of work and employment leads either to decreased participation in other regenerative areas of life or to the fact that this participation can only be maintained with a great amount of effort and thus the regenerative potential of these areas of life is no longer experienced. This is what Ms. A meant: "I then put all my strength into my work and make sure that I don't miss work or at least only a little. And because of this, my private life (...) has just gone under".

The following statement by Ms. C., in which she describes her favorite pastime, floral arranging, convincingly shows that particularly meaningful, creative leisure activities can lead to flow experiences that can push the experience of pain into the background for a certain period of time, allowing clients a pain-free phase of regeneration: "Because I have to think about what kind of wreath I want to make, what colors should I put on it, what candle fits (...) That is a very big task. (...) I forget everything else in the world, really. I only concentrate on that (...) and that's why (...) the pain is just gone".
Exhaustion may restricts professional and social opportunities for participation. From the client's point of view, this is not only dependent on personal factors but also factors such as available socioemotional and economic resources in the immediate social environment (see Fig. 2). Examples of these include the resources of employers in the management of workers with chronic pain, for example, via their human resources department, know-how in the area of social security, funding opportunities for assistive technology or measures such as standing desks. A number of interviewees reported that they had experienced being supported at work, which has a relieving effect on their entire life conduct, thus promoting participation in the life area of work and employment over the long term. They mentioned, for example, flexible, customizable work hours or institutionalized opportunities for regeneration at the workplace. Others reported that their employers quickly reached their limits in supporting them. They reported that the financial pressure or a lack of knowledge about social insurance could lead their employers to show little flexibility in the adaptation of work situations. For example, Ms. C reported that she was let go from her position in a small restaurant after she had told her employer that she had to undergo a back operation and would therefore be absent for several weeks. In a private context, as is evident in Fig. 2, apart from knowledge about chronic pain, empathy and the attitudes of friends and colleagues are the main factors influencing living with chronic pain. A lack of understanding and misinterpretation of the behavior of people who are affected by chronic pain can, over time, lead to exclusion from social networks and, through this, may have an effect on their energy levels. The following quote from Ms. G demonstrates the complex interaction between pain, exhaustion, activity and participation: "For many people it has been difficult afterwards, if you say 'we (... ) are doing something together' and after that, the situation was that I ( . . ) could hardly walk, and afterwards one had to cancel again and again, and that of course also led to people distancing themselves more and more. It's clear (...) you set a date to meet and later, you have to say, somehow, in the morning, 'you know, it's not possible now'. And many people can't imagine what it's like when you're in constant pain. And then they have the feeling, yeah, they don't feel like, or they just don't want to, and that's been difficult". This went so far that Ms. G, "in the end (...) actually had no one [left]." Understanding and empathy in one's circle of friends 
can conversely make living with pain much easier, as becomes clear in the example of Ms. H: "Of course, the environment has helped. So I'm still saying that without these people around you, who make you feel that you're just as important and you have their support and have sympathy, so to speak, so without that nothing would have worked. So, of course this has contributed a lot".

These quotations lead to the second mechanism, identified as influential in the pre-interventional phase: experiences of discrimination or lack of social affirmation (see Fig. 2). These are to be understood as experiences of not being understood by other people or of encountering distrust and rejection. On the one hand, this mechanism is influenced by personal factors. This is what Mr. D self-critically reported, that some of the negative experiences he has had in the health care sector are probably also due to his own weaknesses in communicating about his pain: "This is perhaps also a reason that I have sometimes not been taken so seriously. I just said, 'Here is a problem [points to a site on the body], Here is a problem' [points to another site on the body]". On the other hand, environmental factors such as the attitudes or communication skills of health professionals play a central role. All interviewees agreed that as sufferers from pain, they had repeatedly suffered from prejudice, stigma and being treated as psychiatric cases in the health and social care system. An example is the statement by Mr. D: "He [the neurologist, note tf] didn't take me seriously either and said, yes, I had a mental health problem. I've heard that hundreds of times"'. It is the repeated experience of a lack of understanding on the part of social and health professionals that seems to lead to extreme shock and resignation, but also to massively reduced confidence in the health care system.: "A doctor gave me an X-ray there and said afterwards that he could
X-ray hundreds of women my age and they would have worse X-rays and no pain. So, that was where I had to say, 'Well, does he not believe me? So, am I actually imagining it? (...) Am I crazy? So I'm stupid?"

In particular, when social security entitlements are clarified, this lack of understanding can turn into mistrust, which can have quite a detrimental effect on those suffering from chronic pain. For instance, in the handling of the clarification of disability insurance claims, an interviewee stated that the mistrust and accusations led to her having to go to inpatient psychiatric treatment: "The expert appraisal was the worst. That then gave me eight and a half weeks of psychiatry".

In summary, it can be said that from the point of view of interviewees that pre-intervention, various personal and environmental factors have a lasting effect as facilitating factors or barriers to professional and social participation as well as self-confidence as a mental factor. The three outcomes are closely intertwined and are not often thought of as being independent of one another, but rather, as part of an entire life conduct. These outcomes are mediated by the two main mechanisms of "pain-associated exhaustion" and "lack of social affirmation". This pre-interventional dynamic, in which environmental factors are important, must be taken into account in pain rehabilitation programs, as it significantly shapes the opportunities and abilities of clients to engage in a program, as is described in the next section.

\subsection{The intra-interventional phase: Recognition as a prerequisite for the ability to engage}

Regarding the intra-interventional phase, our data analysis revealed that, on the basis of their biographical experiences of pain, the interviewees

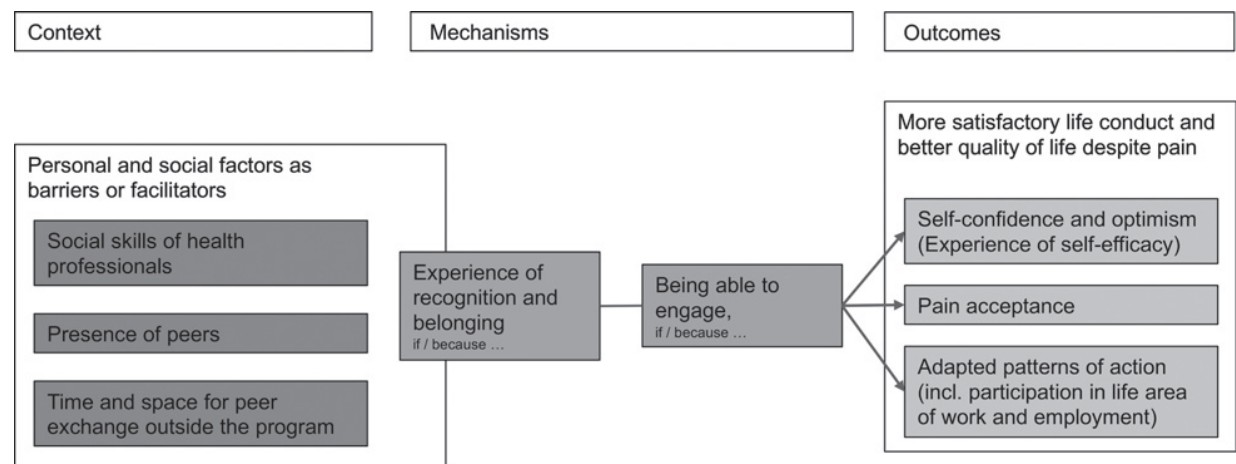

Fig. 3. Intra-interventional CMO configurations. 
consider the interplay of the two mechanisms "experience of recognition and belonging" and "being able to engage" as essential (see Fig. 3). In their view, these mechanisms are a prerequisite for them to be able to engage with and process the content of the program (which is not central to this study). Based on the data, we understand recognition and belonging as two closely connected concepts of satisfaction of basic psychological and social needs for affirmation, respect, benevolence, understanding and belonging in a community. Or, as Ms. G put it: "the feeling of being protected". The social support factor "experience of recognition and belonging" which conveys security is therefore the basis for the second relevant mechanism "being able to engage", which can be regarded as a mental support factor.

Interviewees, some of whom had experienced a lack of social affirmation for years, reported that in the program being examined they noticed for the first time that they were not alone with their pain and that their experiences and feelings were taken seriously: "Yes, you realize afterwards - maybe for the first time really - that you aren't the only one with this pain and that you're not so odd at all (...) because otherwise you are actually always mixing with 'healthy people' so to speak. (That) also gives you a sense of belonging, of course". Making these experiences possible is dependent on various contextual factors. On the one hand, these are the attitudes and basic competences of health professionals (in particular empathy and communication skills). This is how Mr. D replied when asked about why he was able to benefit from the program: "It has something to do with communication. (...) So I've had a few doctors [before the program, note tf] who really made me feel like an outcast. And here [in the program, note tf] they asked me things and tried to develop something and so I felt taken seriously afterwards".

On the other hand, however - and this seems to be central for the clients - these experiences of recognition and belonging happen during exchanges with peers. The interviewees reported that it was the first time they had ever met with "people who were just as affected" when they attended the BAI program. This constitutes a key experience in their pain biography. The two statements of Ms. E and Ms. A are an example of this: "It's like when you've been talking to a wall for years and there's just nothing coming back, and now there are people standing at that wall and they're saying to you, 'Yeah, it's like that'." and "I've learned [in the group, note tf] that it is okay to have this pain and that it is not simply conceited and that it is the same for others". The group was described by various interviewees as a "second family" or "replacement family" and acts as a motivator. "I believe, that's really the most important thing. And to get support or motivation 'yes, come on, we're doing this now, you can do it too', pulling along, sharing. And sometimes having fun in between, of course". In particular, informal exchanges in the group are of central importance from the clients' point of view. The interviewees reported on early morning conversations, joint lunch breaks and evening conversations. These informal exchanges require a protective framework, however, which is not to be found naturally in a hospital environment and must first be created as a prerequisite for clients' interpersonal encounters. As Ms. A puts it: "I also noticed that this possibility to retreat as a group was not there. Like maybe at noon being able to sit together somewhere undisturbed and not downstairs in the cafeteria, where there are 7000 others". However, the feeling of recognition and belonging can be very fragile. For example, the interviewees mentioned negative influencing factors in the form of organizational ambiguities such as inaccurate rehabilitation plans, unpredictable changes of contact persons and lack of transparency (e.g. in the case of unjustified unequal treatment of clients).

In summary, it can be said that some clients had suffered from a lack of social affirmation before the program and had lost confidence both in health professionals and in themselves and other relevant social systems. The exchange of views with "equally affected persons" and the social competence of health professionals seemed to be important prerequisites for first involving themselves in the program in a beneficial way therefore having the chance to achieve the intended program objectives such as pain acceptance or the return to work. The two mechanisms "experience of recognition and belonging" and "being able to engage" play important roles in this. This dynamic, however, in which environmental factors are important, in particular as a support factor, is strongly challenged after the end of the program because, as described in the next section, essential support factors 'fall away'.

\subsection{The post-interventional phase: Implementation competence of new patterns (volition)}

The sustainability of program outcomes is strongly influenced by two other mechanisms that naturally only come into effect after the end of the program. 
Even in the BAI program, which is designed explicitly so that independence and implementing what has been learned in everyday life continuously increases in every program phase, the completion of the program is considered by many participants to be a turning point: "After that, this program stops, then there is something like a cut and afterwards you are alone again". The 'falling away' of the rehab framework and the transition from the program into one's private life cause volitional competences to be strongly challenged. The term "rehab framework" denotes all structuring, supporting or mandatory elements connected to the program, which are no longer present after the end of the program. This includes, for example, the obligation to participate regularly or have informal discussions with peers. The category of volitional competences includes all the elements mentioned in the interviews of the interactions between thoughts, feelings, knowledge and actions that serve to help implement and consolidate program outcomes in everyday life. However, regarding outcomes such as the ability to participate in the life area of work and employment, it is not only the volitional competences of the people directly affected, but also those of their social environment (e.g. the employer or the family), which decide whether the newly-learned patterns can be sustainably anchored in everyday private or work life. Whether and how this mechanism is activated is influenced here again by different environmental and personal contextual factors. For example, habits or needs related to movement play a role. For example, with regard to physiotherapy exercises, more active or movement-seeking interviewees reported that making exercising part of their everyday life was achieved without great effort, whereas interviewees with more movement-avoidant behavioral habits reported that implementing the exercises in their everyday life was a great effort.

Some interviewees felt overwhelmed by the prospect of sustainably changing well-established patterns that had formed over years within a few weeks. For these development processes they needed support over a longer period of time, also in everyday life post-intervention. As Mr. B thought: "The mechanisms, that's just something that's there and I'm just saying that a twenty-four- or five-year-old will manage relatively quickly but if you're over thirty or thirty-five or fifty like me, that's extremely difficult to relearn". And Ms. G., who considered herself to be failing in the implementation of what she had learned, said: "No it didn't work - and probably didn't for many others - because it should actually be possible that it could be longer. Because until I went into this program, I'd maybe had eight years of pain. So I (.. .) have like a 'learned structure' and I can't change that within three months, when I've already had it for a very long time. And that's why I feel that it should have gone on much longer after the program, that there should have been further support, so that it could really have been consolidated”. Ms. G. spoke about the importance of maintenance offers after the actual intervention.

The same sentiment was expressed by Mr. B on the implementation of exercises in his everyday life. Aware of his own limited volitional competences, he would have wished to be able to organize opportunities for sharing amongst his peers: "Yeah, it just pisses me off, there's no one who you can talk to, there's no one there with the same problem. (...) Of course, if this group stays together somehow afterwards or is monitored together, I think that's more like it. Okay, it's a personal responsibility that you should take on. But I'm just too weak." In particular, clients desire maintenance programs if they are less involved in social networks, or have fewer opportunities to discuss their pain with family or in their circle of friends. Their ideas range from the initiation and moderation of self-help groups and further support during fitness training to psychosocial counseling services. Another influential contextual factor is the differing development processes, which program participants as well as their social environment experience for the duration of the program. This can be a "development gap" between those affected and their environment, if the relevant parts of the social environment are not sufficiently involved in the process, which can further disturb the already fragile life conduct balance. These developmental differences can take place at the level of knowledge, but also of attitudes, emotions or behavior change and affect both the private and professional environment. A negative example was reported, for example, by Mrs. A., in which reintegration into the life area of work and employment after rehab was made more difficult as her employer was not sufficiently involved during the program and in the end was not prepared to adjust her shift schedules for the re-entry phase: "I remember that the idea was that I should have been able to work $60 \%$ again, and actually the idea was that once a week I could work a whole day. But for the company this was not possible, they didn't want to be able to do that".

In summary, it can be said that, from the point of view of the interviewees, the program outcomes 


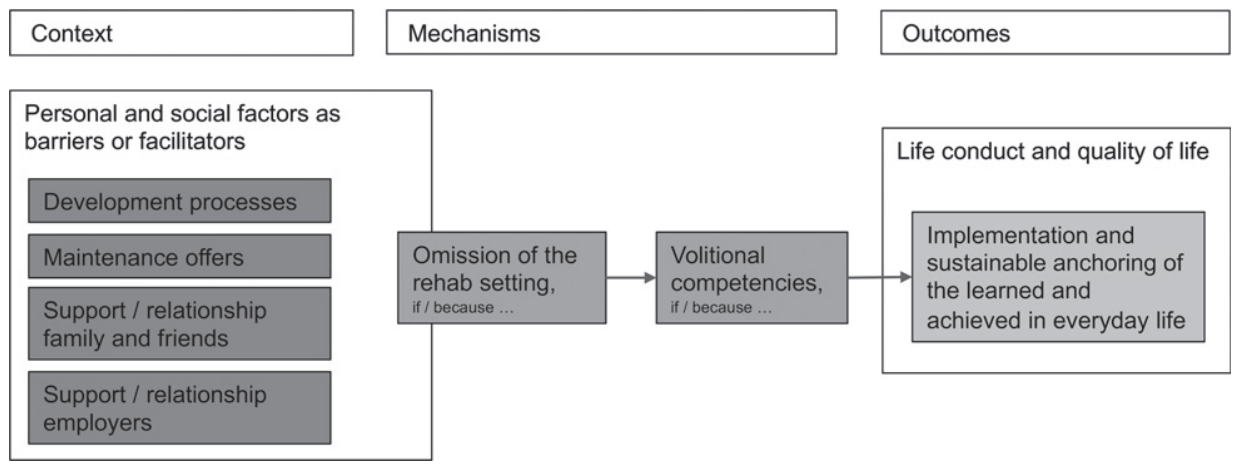

Fig. 4. Post-interventional CMO configurations.

such as reintegration into the life area of work and employment are not only influenced by pain and the associated impaired functioning, but also by different environmental and personal contextual factors acting as supporting factors or barriers. The 'falling away' of a rehabilitation framework and the volitional competences of the social environment shape the interviewees' ability to implement acquired skills and capabilities in everyday life after rehabilitation.

\section{Discussion}

The findings of the study have shown that it makes sense for pain rehabilitation programs to consider clients' ability to participate in the life area of work and employment in connection with their ability to participate in other areas of life. This is because clients report a complex interplay of diverse, overarching contextual life factors. In their experience, chronic pain limits the resources available for their life conduct, which can lead to some areas of life no longer being actively maintained or cared for. The 'falling away' of these areas of life can lead to an imbalance in the entire life conduct system, which also threatens their ability to participate in the life area of work and employment.

In the clients' view, both environmental and personal factors play a role in achieving the outcomes of the program and ensuring their sustainability in everyday life. Figure 5 shows the contextual factors that have proved relevant in this study, presented as components of the ICF.

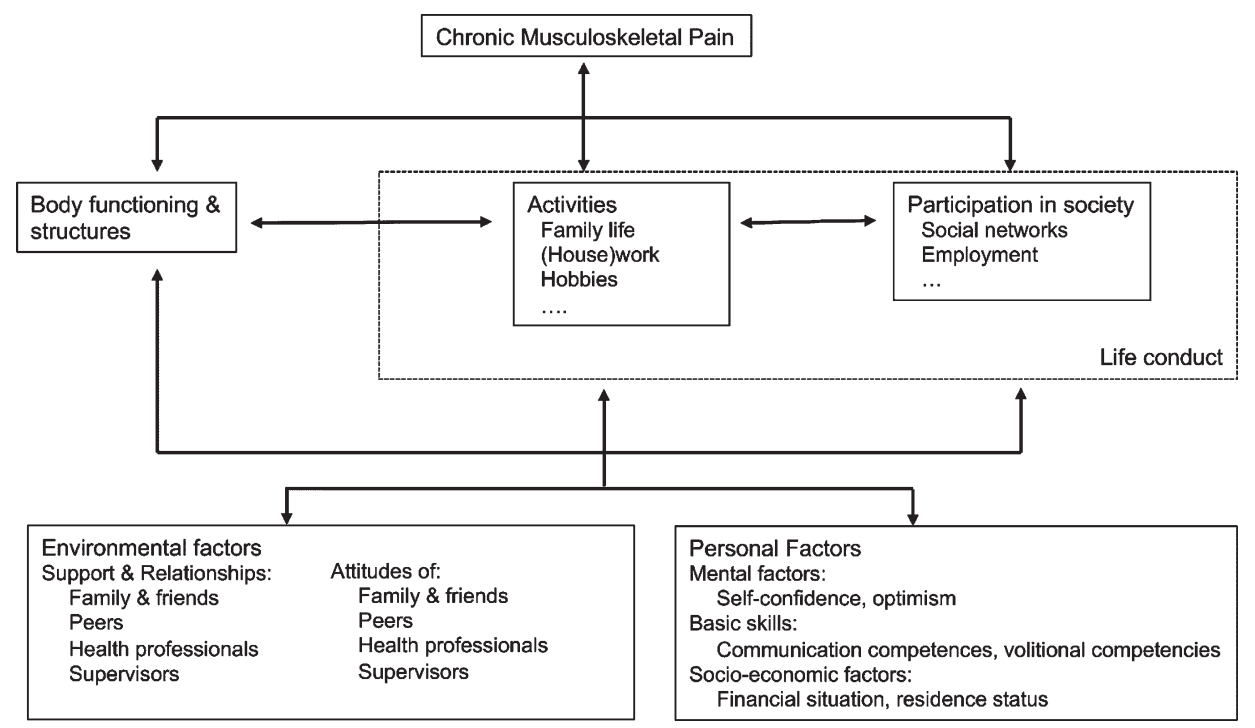

Fig. 5. Overview of relevant activities, participation, environmental and personal factors as contextual factors of a rehabilitation program. (Basic framework: WHO, 2001). 
In the study, the interplay of the various factors was condensed into a few central CMOCs (see Figs. 2-4). In addition, there are other secondary CMOCs, which cannot be discussed here. The published CMOCs are to be understood as the product of the evaluation, as working hypotheses and as a contribution to a more detailed program theory.

In the pre-interventional phase, i.e. the phase of the development and maintenance of chronic pain, socio-economic factors and factors in the social environment such as support, relationships and attitudes have proven to be particularly influential. It is known from qualitative and quantitative studies [16, 26-30] that social and socio-economic factors and workplace situations play essential roles in the development and maintenance of chronic pain, but also in participation in life area of work and employment despite chronic pain. In their studies, McCluskey et al. were able to find evidence of a link between family support and staying in the workplace. But they also point out that the significance of the social dimension in the biopsychosocial model of health is still underexposed [16]. The findings of this study show that these contextual factors, through the mechanisms of experiences of discrimination and exhaustion, may affect not only the genesis and persistence of the disease, but also the ability to be engaged in treatment, thus impacting reintegration into the life area of work and employment. For the practice of interprofessional pain rehabilitation programs, this means, that an early, thorough and professional diagnosis of the social situation can be an important source of information for planning support.

In the intra-interventional phase, the early involvement of employers, the social competence of health professionals and the presence and exchange with peers have all proved to be influential. In particular for people in precarious professional situations, it seems of central importance to involve the employers in the process at an early stage, so that the process of returning into the life area of work and employment after rehab can be successful. Furthermore, the experience of being taken seriously and the realization that one is not alone with one's pain are important prerequisites for being able to engage in the treatment. It could therefore be useful for a rehabilitation program to create possibilities for the participants to exchange ideas undisturbed and unobserved even outside the actual program, because such possibilities promote the "ability to engage" in the program and its contents, provided that the informal exchange by the participants can be designed constructively. This informal exchange enables experiences of recognition and belonging, which are, as it were, counter-experiences to pre-interventional experience. They form the basis for affected persons' ability to develop convictions of self-efficacy and thereby engage in the program and its content in a productive way. At this point, if not before, parallels to recovery processes for mental illnesses are striking. The importance of the contextual factors and mechanisms portrayed above, as well as systematic offers and follow-up care, is also addressed in research on recovery processes in mental illness [31, 32]. These parallels are not particularly surprising considering that, in the overarching sense, rehabilitation programs for chronic illness are always about a return to a satisfactory life conduct despite continuing limitations $[33,34]$. This brings us to the central findings of the post-interventional phase.

The most relevant contextual factors in the postinterventional phase have proved to be the 'falling away' of the framework provided by the pain rehabilitation program and the competence to transfer what has been learned into everyday life and to implement it sustainably. For interprofessional rehabilitation programs, this means two main things: First, the importance of creating post-rehabilitative treatment services, and second, the importance of strengthening volitional competences during intervention. Based on our analysis and the use of a social or occupational therapy scientific understanding of volition [35, 36], we propose an understanding of volitional competence in rehabilitation not only as individual competence but also as the competence of social systems. Accordingly, we recommend not only strengthening the clients in their volitional competence, but also supporting their social environment (family members and employers), since their knowledge and motivation have a significant influence on the volitional competences of the whole system. This recommendation is in line with findings, for example, from Nilsson et al., who report in connection with return to work processes of stroke patients that employers consider their lack of knowledge of the condition and support strategies to be one of the biggest challenges for the successful return of their employees into the workplace [37]. In a meta synthesis of qualitative pain research, Snelgrove and Liossi also recommend not only supporting the people directly affected, but also creating educational and support services for the relatives [29]. On the one hand, these measures can contribute to the ability of relatives themselves to deal better with their own situation. On the other hand, it contributes to their ability 
to support their family members directly affected by pain in a more targeted way.

\section{Conclusion}

The main finding of the present research is that the ability to participate in the life area of work and employment as described above is always to be understood as interdependent with the ability to participate in other areas of life. In program theory, the ability to participate in the life area of work and employment should therefore be understood in this broad sense. Likewise, assessment, evaluation and treatment should be carried out based on this understanding.

Based on the main finding, five important additional findings regarding participation in the field of work can be summarized for interprofessional pain rehabilitation programs:

1. Context matters. Both environmental and personal factors function as contextual factors influencing the sustainability of the program outcomes.

2. The opportunity to have (informal and formal) exchange with peers can support the ability of clients to engage in program content.

3. The social skills of health professionals (especially communication skills and empathy) influence the ability of clients to engage in program content.

4. Volitional competence in rehabilitation programs is to be understood as an overall system's implementation ability.

5. Maintenance services can support the sustainable implementation in everyday life of what has been learned.

Based on these findings, we make the following recommendations for complex, interprofessional rehabilitation programs for people with chronic pain:

1. The development of an interprofessional, integrative understanding of work ability as participation in the life area of work and employment. This should place participation in the life area of work and employment in the context of the entire life conduct, in order to ensure the sustainability of the program.

2. Identification, thematization and processing of relevant contextual factors. As a first step, we recommend that every client be provided with a comprehensive social diagnosis by professionals (e.g. clinical social workers), from which goals and measures for inclusion and participation are formulated.

3. The creation of sufficient informal opportunities to exchange views with peers within the framework of the program.

4. That in the recruitment of personnel (incl. medicine), as well as professional competence, particular attention should be paid to social competences such as person- and situationoriented communication.

5. The early involvement of the social environment, so that the needs of relatives and employers can be clarified and they can be supported with expertise in their contribution to the process. This includes not only timely involvement in discussions, but also the creation of institutionalized vessels for family education and counselling.

6. The installation of maintenance services for people who have completed the program and, if necessary, for their relatives. These could, for example, include guided groups, self-help groups or, based on the recovery theory, services led by experienced peers.

Like any study, the present study has strengths and limitations. In what follows, the key strengths and limitations are briefly discussed. The application of the content-structuring qualitative content analysis according to Kuckartz, in the framework of a realist evaluation, has to date not been extensively evaluated. Nevertheless, it seems to us to be an innovative contribution to the discourse on the methodological design of the evaluation of complex programs in the health care sector. The findings of the study could not be validated communicatively with the interviewees. However, the plausibility of the study's findings is supported by the resulting high density of the analysis. In addition, it was reviewed in a continuous process of reflection with peers. The findings of this study apply primarily to the program evaluated. They cannot be generalized as a description of the influence of contextual factors on the ability to participate in the life area of work and employment by all people affected by chronic pain. However, they are, in reference to Peräkylä [38], generalizable as a description of how contextual factors can affect the ability of people to work with chronic pain. The CMOCs described were reconstructed from the experiences of the interviewees. They need to be 
corroborated with further methodological approaches to proof their validity. As mentioned above, we were able to interview eight patients in this study. We were able to identify relevant CMOCs. Although no fundamentally new mechanisms or contextual factors were found from the sixth interview onward and the category system has solidified, we cannot exclude the possibility that other relevant contextual factors and mechanisms exist that were not mentioned by the interviewees. Two quantitative studies are currently underway in which the influence of contextual factors on the ability of people with chronic pain to participate in the life area of work and employment by means of registry studies are being investigated.

\section{Acknowledgments}

We would like to thank our interviewees for their willingness to participate in this study. We would also like to thank the BAI team for their tireless work and our academic peers for their constructive contributions to the discussion of this research and its findings. Furthermore, we would like to thank Prof. Dr. Daniel Gredig, Prof. em. Dr. med. Peter M. Villiger, Dr. Joel Gautschi, and the translators A. Scarlotta and M. Oertig for their support.

\section{Conflict of interest}

None to report.

\section{References}

[1] World Health Organization. International Classification of Functioning, Disability and Health (ICF) 2001. https://apps.who.int/iris/handle/10665/42407 (accessed February 10, 2020).

[2] Breivik H, Collett B, Ventafridda V, Cohen R, Gallacher D. Survey of chronic pain in Europe: prevalence, impact on daily life, and treatment. European Journal of Pain. 2006;10:287-333. https://doi.org/10.1016/ j.ejpain.2005.06.009

[3] Gaskin DJ, Richard P. The Economic Costs of Pain in the United States. The Journal of Pain. 2012;13:715-24. https://doi.org/10.1016/j.jpain.2012.03.009

[4] Becker N, Hojsted J, Sjogren P, Eriksen J. Sociodemographic predictors of therapeutic results in patients with chronic, non-malignant pain. Ugeskrift for Laeger. 2001;163:3073-7.

[5] Gantschnig BE, Heigl F, Widmer Leu C, Bütikofer L, Reichenbach S, Villiger PM. Effectiveness of the Bern Ambulatory Interprofessional Rehabilitation (BAI-Reha) programme for patients with chronic musculoskeletal pain: a cohort study. Swiss Medical Weekly. 2017. https://doi.org/10.4414/smw.2017.14433

[6] Westhorp G. Realist Impact Evaluation - an Introduction. London: Overseas Development Institute; 2014.

[7] Pawson R, Tilley N. Realist Evaluation. London: Cabinet Office; 2004.

[8] Haunberger S. Realistic Evaluation als Evaluationsrahmen in der Klinischen Sozialarbeit. In: Hahn G, Hüttemann M, editors. Evaluation psychosozialer Interventionen, Köln: Psychiatrie Verlag; 2015.

[9] Grotkamp S, Cibis W, Nüchtern E, von Mittelstaedt G, Seger W. Personal Factors in the International Classification of Functioning, Disability and Health: Prospective Evidence. Australian Journal of Rehabilitation Counselling. 2012;18:1-24. https://doi.org/10.1017/jrc.2012.4

[10] Lacouture A, Breton E, Guichard A, Ridde V. The concept of mechanism from a realist approach: a scoping review to facilitate its operationalization in public health program evaluation. Implementation Science. 2015;10:153. https://doi.org/10.1186/s13012-015-0345-7

[11] Westhorp G. Understanding Mechanisms in Realist Evaluation and Research. Doing Realist Research, Los Angeles, London, New Delhi, Singapore, Washington DC, Melbourne: Sage. 2018, p. 41-57.

[12] Bouwmans C, Hakkaart-van Roijen L, Koopmanschap M, Krol M, Severens H, Brouwer W. Productivity Costs Questionnaire Manual. Rotterdam: Institute for Medical Technology Assessment, Erasmus Universiteit Rotterdam; 2013.

[13] Allgeier L, Bengel J. Factors Influencing Return to Work in Chronic Back Pain. Physik Med Rehabilitationsmed Kurort. 2018;28:103-13. https://doi.org/10.1055/s-0043-124440

[14] Bostan C, Oberhauser C, Stucki G, Bickenbach J, Cieza A. Which environmental factors are associated with performance when controlling for capacity? J Rehabil Med. 2014;46:806-13. https://doi.org/10.2340/165019771839

[15] Hara KW, Bjørngaard JH, Jacobsen HB, Borchgrevink PC, Johnsen R, Stiles TC, et al. Biopsychosocial predictors and trajectories of work participation after transdiagnostic occupational rehabilitation of participants with mental and somatic disorders: a cohort study. BMC Public Health. 2018;18:1014. https://doi.org/10.1186/s12889-018-5803-0

[16] McCluskey S, de Vries H, Reneman M, Brooks J, Brouwer S. "I think positivity breeds positivity": a qualitative exploration of the role of family members in supporting those with chronic musculoskeletal pain to stay at work. BMC Fam Pract. 2015;16:85. https://doi.org/10.1186/s12875015-0302-1

[17] McCluskey S, Brooks J, King N, Burton K. Are the treatment expectations of "significant others" psychosocial obstacles to work participation for those with persistent low back pain? Work: Journal of Prevention, Assessment \& Rehabilitation. 2014;48:391-8. https://doi.org/10. 3233/WOR-131789

[18] McCluskey S, Brooks J, King N, Burton K. The influence of "significant others" on persistent back pain and work participation: a qualitative exploration of illness perceptions. BMC Musculoskelet Disord. 2011;12:236. https://doi.org/10.1186/1471-2474-12-236

[19] de Vries HJ, Brouwer S, Groothoff JW, Geertzen JHB, Reneman MF. Staying at work with chronic nonspecific musculoskeletal pain: a qualitative study of workers' experiences. BMC Musculoskelet Disord. 2011;12:126. https://doi.org/10.1186/1471-2474-12-126 
[20] Patel S, Greasley K, Watson PJ. Barriers to rehabilitation and return to work for unemployed chronic pain patients: a qualitative study. Eur J Pain. 2007;11:831-40. https://doi.org/10.1016/j.ejpain.2006.12.011

[21] Patton MQ. Qualitative Research \& Evaluation Methods. 4th ed. Thousand Oaks, London, New Delhi: Sage; 2015.

[22] Kuckartz U. Qualitative Inhaltsanalyse. Methoden, Praxis, Computerunterstützung. 4. Auflage. Weinheim Und Basel: Beltz Juventa; 2018.

[23] Witzel A. The Problem-centered Interview. Forum Qualitative Sozialforschung / Forum: Qualitative Social Research. 2000;1:Art. 22. https://doi.org/10.17169/fqs-1.1.1132

[24] Corbin J, Strauss A. Basics of Qualitative Research - Techniques and Procedures for Developing Grounded Theory. 4th ed. Los Angeles: Sage; 2015.

[25] Sommerfeld P, Hollenstein L, Calzaferri R. Integration und Lebensführung - Ein forschungsgesteuerter Beitrag zur Theoriebildung der Sozialen Arbeit. Wiesbaden: VS Verlag; 2011.

[26] Nickel R, Raspe HH. Deskriptive Schmerzepidemiologie. In: Egle U, Hoffmann S, Lehmann K, Nix W, editors. Handbuch chronischer Schmerz, Stuttgart: Schattauer; 2003, p. 105-17.

[27] van Hecke O, Torrance N, Smith BH. Chronic pain epidemiology - where do lifestyle factors fit in? British Journal of Pain. 2013;7:209-17. https://doi.org/10.1177/ 2049463713493264

[28] de Vries HJ, Reneman MF, Groothoff JW, Geertzen JHB, Brouwer S. Workers who stay at work despite chronic nonspecific musculoskeletal pain: do they differ from workers with sick leave? J Occup Rehabil. 2012;22:489-502. https://doi.org/10.1007/s10926-012-9360-6

[29] Snelgrove S, Liossi C. Living with chronic low back pain: a metasynthesis of qualitative research. Chronic Illness. 2013;9:283-301. https://doi.org/doi:10.1177/17423 95313476901

[30] Nilsen G, Anderssen N. Struggling for a normal life: Work as an individual self-care management strategy among persons living with non-malignant chronic pain. Work. 2014;49:123-32. https://doi.org/10.3233/WOR-131642
[31] Brown W, Kandirikirira N. Recovering mental health in Scotland - Report on narrative investigation of mental health recovery. Glasgow: Scottish Recovery Network; 2008.

[32] Onken SJ, Dumont JM, Ridgway P, Dornan DH, Ralph RO. Mental Health Recovery: What Helps and What Hinders? A National Research Project for the Development of Recovery Facilitating System Performance IndicatorsPhase One Research Report. Alexandria, VA: National Association of State Mental Health Program Directors (NASMHPD) National Technical Assistance Center (NTAC); 2002.

[33] Anthony WA. Recovery from mental illness: The guiding vision of the mental health service system in the 1990s. Psychosocial Rehabilitation Journal. 1993;16:11-23. https://doi.org/10.1037/h0095655

[34] Universitätsklinik für Rheumatologie, Immunologie und Allergologie des Universitätsspitals Bern (Inselspital). BAI -Reha: Das Berner ambulante interprofessionelle muskuloskelettale Rehabilitationsprogramm für Schmerzpatienten /-innen - BAI -Reha: The Bernese Outpatient Interprofessional Musculoskeletal Rehabilitation Program for Patients with Chronic Pain 2017.

[35] Fuchs P. Das Mass aller Dinge: eine Abhandlung zur Metaphysik des Menschen. 1. Aufl. Weilerswist: Velbrück Wissenschaft; 2007.

[36] Kielhofner G, Mentrup C, Niehaus A. Das Model of Human Occupation (MOHO): Eine Übersicht zu den grundlegenden Konzepten und zur Anwendung. In: Jerosch-Herold C, Marotzki U, Hack BM, Weber P, editors. Konzeptionelle Modelle für die ergotherapeutische Praxis, Berlin, Heidelberg: Springer; 1999, p. 49-82. https://doi.org/10.1007/978-3-662-08173-0_4

[37] Nilsson AÖ, Eriksson G, Johansson U, Hellman T. Experiences of the return to work process after stroke while participating in a person-centred rehabilitation programme. Scandinavian Journal of Occupational Therapy. 2016. https://doi.org/10.1080/11038128.2016.1249404

[38] Peräkylä A. Reliability and validity in research based upon transcripts. In: Silverman D, editor. Qualitative Research, London: Sage; 1997, p. 201-19. 